\title{
INTERNALISASI NILAI PANCASILA DALAM PEMBELAJARAN MELALUI PENERAPAN PROFIL PELAJAR PANCASILA BERBANTUAN PLATFORM MERDEKA MENGAJAR
}

\author{
Internalization of Pancasila Values in Learning through \\ Implementation of Pancasila Student Profile with "Merdeka \\ Mengajar" Platform
}

\author{
Eni Susilawati, Saleh Sarifuddin \\ Pusat Data dan Teknologi Infornasi, Kementerian Pendidikan, Kebudayaan, Riset, dan \\ Teknologi \\ JL. RE. Martadinata KM 5,5, Ciputat, Tangerang Selatan \\ ensiwa15@gmail.com; saleh.sarifudin@kemdikbud.go.id
}

\author{
Suyitno Muslim \\ Pascasarjana UNJ Jakarta
}

JI. Pemuda No.28, RT.11/RW.14, Rawamangun, Jakarta Timur

suyitno@unj.ac.id

Diterima:

08 Desember 2021

Direvisi:

09 Desember 2021

Disetujui:

10 Desember 2021
ABSTRAK: Salah satu tantangan bagi dunia pendidikan saat ini adalah bagaimana mengembangkan pendidikan karakter bagi siswa selama masa new normal. Kemendikbudristek menetapkan 6 indikator dari Profil Pelajar Pancasila. Guna mempermudah internalisasi Profil Pelajar Pancasila dalam pembelajaran baik oleh guru maupun siswa, dikembangkan Platform Merdeka Mengajar (PMM). Penelitian ini bertujuan untuk mengetahui penerapan pemanfaatan Platform Merdeka Mengajar dalam menginternalisasi nilai-nilai Pancasila. Sampel penelitian adalah guru-guru sekolah penggerak dan SMK Pusat Keunggulan yang telah mengikuti bimtek PMM tahun 2021. Pengumpulan data menggunakan kuesioner, observasi dan wawancara terbatas. Hasil penelitian menunjukkan bahwa: 1)Profil Pelajar Pancasila pada hakikatnya merupakan salah satu upaya internalisasi nilai-nilai Pancasila dalam pembelajaran, 2) PMM memiliki peran signifikan dalam penerapan Profil Pelajar Pancasila pada pembelajaran paradigma baru, dan 3) Internalisasi nilai-nilai Pancasila dalam penerapan Profil Pelajar Pancasila di masa new Normal berbantuan Platform Merdeka Mengajar dengan cara diterapkan dalam karakter keseharian yang dibangun dan dihidupkan dalam diri individu setiap pelajar melalui budaya sekolah, pembelajaran intrakurikuler, kokurikuler, maupun ekstrakurikuler di sekolah. Peningkatan pemanfaatan Platform Merdeka Mengajar dalam menginternalisasi nilai-nilai Pancasila melalui Profil Pelajar Pancasila, perlu didukung dengan upaya peningkatkan kualitas dan kuantitas konten Profil Pelajar Pancasila serta dukungan kebijakan dalam pemanfaatan PMM dan sinergi kolaborasi antara sekolah, pemerintah, masyarakat serta pemangku kepentingan. PMM dapat menjadi salah satu solusi dalam penguatan pembelajaran karakter melalui internalisasi nilai Pancasila bagi siswa generasi milenial, terutama pada saat pembelajaran tatap muka terbatas di masa new normal pandemi Covid-19. 
Kata kunci: PMM, Profil Pelajar Pancasila, Internalisasi nilai Pancasila

ABSTRACT: One of the challenges in education today is student character education during the new normal era. The Ministry of Education, Culture, Research, and Technology sets 6 indicators of the Pancasila Student Profile. To enhance the internalization of the Pancasila Student Profile in learning by both teachers and students, the Merdeka Mengajar Platform (MMP) is developed. The objective of this research is to know the implementation of MMP in internalizing the values of Pancasila. The sample is teachers of driving schools and Center of Excellence Vocational Schools who have participated in the PMM technical guidance in 2021. Data collection is through questionnaires, observation, and limited interviews. The result show that: 1) Pancasila Student Profile is essentially an effort to internalize Pancasila values in learning; 2) MMP has significant roles in the implementation of the Pancasila Student Profile in the new learning paradigm; and 3) The internalization of Pancasila values in the implementation of Pancasila Student Profile in the new normal era with MMP is applied in daily characteristics that are developed and enhanced in every student through school culture, intra-curricular, co-curricular, and extra-curricular learning at school by applying it to the daily character that is built and brought to life in each student through school culture, intra-curricular, co-curricular, and extra-curricular learning at school. The improvement of MMP implementation in internalizing Pancasila values through Pancasila Student Profile should be supported by increasing the quality as well as quantity of Pancasila Student Profile contents, by policies in MMP implementation, and collaboration between schools, government, and other stakeholders. MMP can be one of the solutions to enhance character education through the internalization of Pancasila values for millennial students, especially during the limited face-to-face learning in a new normal era of pandemic covid-19.

Keywords: Merdeka Mengajar Platform, Pancasila Student Profile, Internalization of Pancasila values

\section{PENDAHULUAN}

Peran Pendidikan bagi rakyat Indonesia sangat penting, diantaranya untuk meningkatkan potensi dan kompetensi, membangun karakter bangsa yang memiliki martabat dan adab, yang bertujuan mencerdaskan kehidupan bangsa." Sehingga, masalah pendidikan tidak hanya berkaitan dengan kompetensi belajar, tetapi juga pembentukan karakter siswa. Keberhasilan pendidikan tidak hanya bergantung pada wawasan dan kompetensi teknis (hard skill), namun juga pada keterampilan karakter (soft skill), sehingga peningkatan kualitas pendidikan karakter siswa sangatlah penting (Suwartini, 2017). Selama pandemi covid 19 dan era new normal, dimana pembelajaran berbasis jaringan baik online maupun blended banyak diterapkan pada siswa, berdampak pada pola pendidikan karakter yang agak terbatas. Biasanya guru mengintegrasikan pendidikan karakter dalam proses pembelajaran seharisehari di sekolah, maka selama belajar dari rumah maupun tatap muka terbatas, 
guru menjadi kurang leluasa. Banyak siswa yang asyik dengan belajar daring tanpa memaksimalkan sosialisasi, kerjasama, dan kolaborasi dengan sesama siswa dan/ atau guru yang sarat dengan penanaman sikap/ karakter. Hal ini menjadi tantangan bagi dunia pendidikan bagaimana mengembangkan pendidikan karakter bagi siswa selama masa new normal.

Kebijakan Kementerian Pendidikan dan Kebudayaan yang terdapat dalam Peraturan Menteri Pendidikan dan Kebudayaan Nomor 22 Tahun 2020 tentang Rencana Strategis Kementerian Pendidikan Tahun 2020-2024, (2020) menyebutkan: "Pelajar Pancasila adalah perwujudan pelajar Indonesia sebagai pelajar sepanjang hayat yang memiliki kompetensi global dan berperilaku sesuai dengan nilai-nilai Pancasila, dengan enam ciri utama: beriman, bertakwa kepada Tuhan YME, dan berakhlak mulia, berkebhinekaan global, bergotong royong, mandiri, bernalar kritis, dan kreatif".

Kebijakan Kemendikbudristek mengenai penetapanProfilPelajarPancasilamerupakan salah satu upaya Kemendikbudristek dalam mewujudkan nawacita Presiden Joko widodo yaitu penguatan Pendidikan Karakter (PPK). PPK merupakan kebijakan pendidikan yang memiliki tujuan pokok yaitu menerapkan Nawacita Presiden Joko Widodo dan Wakil presiden Jusuf Kalla dalam sistem pendidikan nasional. Kebijakan PPK ini telah diintegrasikan ke dalam Gerakan Nasional Revolusi Mental (GNRM), yaitu perubahan pola pikir, bertindak serta berperilaku kearah yang lebih baik. Menurut Kosim, (2011), kita perlu sejak usia dini mulai mengajarkan pendidikan karakter secara sistematis dan komprehensif dari metode memahami, mencintai, dan berbuat baik. Metode memahami untuk mengetahui yang baik. Cinta kebaikan adalah perasaan dan cinta seseorang terhadap kebajikan yang diajarkan. Dengan demikian seseorang berkarakter baik akan semakin sadar untuk melakukan perbuatan baik karena dia menyukai perilaku moralitas. Selanjutnya berbuat baik, akan menjadi kebiasaan kebajikan spontan. Apabila semuanya memungkinkan, maka akan muncul orang yang dapat melakukan sesuatu secara spontan menurut nilai-nilai yang telah ditanamkan.

Fenomena masalah yang terjadi di lingkungan pendidikan akhir-akhir ini, menuntut pentingnya program penguatan pendidikan karakter, diantaranya permasalahan degradasi moral. Contohnya adalahkasusintoleran(tawuranantarpelajar), prostitusi, pergaulan bebas, bullying, pornografi dan cyber crime. Hasil riset KPAI menemukan fakta bahwa terjadi peningkatan kasus tawuran pada tahun 2020 di Indonesia dari tahun-tahun sebelumnya. Sementara itu berdasarkan data KPAI, (2020), banyaknya kasus pornografi dan cyber crime pada anak menambah catatan masalah anak (KPAl, 2020b). Sejumlah kasus kenakalan remaja yang dirilis oleh KPAI tahun 2020 tertuang dalam tabel 1 dibawah ini.

Tabel 1. Kasus kenakalan anak

\begin{tabular}{|l|c|c|}
\hline Bentuk Kasus Anak & $\mathbf{2 0 1 9}$ & $\mathbf{2 0 2 0}$ \\
\hline $\begin{array}{l}\text { Anak korban tawuran } \\
\text { pelajar }\end{array}$ & 73 & 9 \\
\hline $\begin{array}{l}\text { Anak korban kekerasan } \\
\text { di sekolah (bulliying) }\end{array}$ & 46 & 76 \\
\hline $\begin{array}{l}\text { Anak korban Pornografi } \\
\text { dan cybercrime }\end{array}$ & 651 & 653 \\
\hline $\begin{array}{l}\text { Anak korban kebijakan } \\
\text { (anak dikeluarkan } \\
\text { karena hamil, pungli di } \\
\text { sekolah, penyegelan } \\
\text { sekolah, tidak boleh ikut } \\
\text { ujian, anak putus } \\
\text { sekolah, drop out, dsb) }\end{array}$ & 67 & 1463 \\
\hline
\end{tabular}

Sumber: bank data KPAI (2020)

Tabel 1 menunjukan bahwa degradasi moral masih terus terjadi, dan ini akan sangat berbahaya bagi kemajuan bangsa Indonesia. Olehkarenaitu, pemerintah telah merumuskan kebijakan pendidikan budaya dan karakter bangsa. Pendidikan karakter merupakan tumpuan bangsa untuk merealisasikan visi pembangunan nasionalnya, yaitu merealisasikan bangsa 
yang memiliki karakter, akhlak yang luhur, moral, budaya, dan adab sesuai ideologi Pancasila dan Undang-Undang Dasar 1945. Pentingnya pendidikan karakter bukan hanya menjadi landasan bagi negara untuk mewujudkanvisi pembangunan nasionalnya saja (Perdana, 2018)it is urgent to know the strategy of strengthening character education in schools to prevent juvenile delinquency. The purpose of this paper is to examine strategies in preventing juvenile delinquency through strengthening character education. This paper uses the theory of habituation from the Skinner, such as spontaneous activities, exemplary methods are also a series of behaviorism theory from John Watson, and conditioning activities that are similar to behaviorism theory from Edwin Guthrie. This study includes the type of literature study research by finding reference theory that relevant to the cases or problems found. The data that have been obtained then analyzed by descriptive analysis method. The conclusions from this literature study includes 1. Menerapkan pendidikan karakter untuk penguatan nilainilai kepribadian/ moralitas pada siswa membutuhkan strategi khusus. Nilai-nilai kepribadian/moralitas yang merupakan nilai pokok PPK yang dimaksud meliputi religius, nasionalisme, kemandirian, gotong royong, dan integritas. Nilai-nilai tersebut akan diterapkan dan dilaksanakan lewat sistem pendidikan nasional sehingga dapat dimengerti, diketahui, dan diimplementasikan dalam semua aspek sekolah dan kehidupan sosial. PPK muncul disebabkan pemahaman terhadap tantangan di waktu yang akan datang yang makin rumit dan tak pasti, akan tetapi pada saat yang sama masyarakat melihat harapan masa depan bangsa. Inilah yang mendesak institusi pendidikan membekali pelajar secara ilmiah dan personal dalam bentuk pribadi yang bermoral, memiliki spiritualisme dan pengetahuan yang kuat, diantaranya melalui Profil Pelajar Pancasila.

Dalam Kalderanews.com (2020), diberitakan Kemendikbud menetapkan 6 indikator dari Profil Pelajar Pancasila. Adapun keenam indikator tersebut seperti tertuang dalam Peraturan Menteri Pendidikan dan Kebudayaan Nomor 22 Tahun 2020 tentang Rencana Strategis Kementerian Pendidikan, (2020). Dalam proses selanjutnya untuk mempermudah internalisasi Profil Pelajar Pancasila dalam pembelajaran baik oleh guru maupun siswa, dikembangkan Platform Merdeka Mengajar, yang salah satu tujuannya adalah untuk mengenalkan dan mengimplementasikan Profil Pelajar Pancasila. Dalam makalah ini penulis ingin membahas lebih khusus mengenai bagaimana internalisasi nilai Pancasila dalam pembelajaran melalui penerapan Profil Pelajar Pancasila berbantuan Platform Merdeka Mengajar". Adapun Rumusan masalahnya sebagai berikut:

1. Bagaimana hakikat Profil Pelajar Pancasila?

2. Bagaimana peran Platform Merdeka Mengajar dalam penerapan Profil Pelajar Pancasila pada pembelajaran paradigma baru?

3 .Bagaimana internalisasi nilai-nilai Pancasila dalam pembelajaran melalui penerapan Profil Pelajar Pancasila di New Normal berbantuan Platform Merdeka Mengajar?

Sebagai usaha mewujudkan profil Pelajar Pancasila diperlukan pembentukan dan penguatan pendidikan karakter bagi pelajar. Menurut Perdana (2018)it is urgent to know the strategy of strengthening character education in schools to prevent juvenile delinquency. The purpose of this paper is to examine strategies in preventing juvenile delinquency through strengthening character education. This paper uses the theory of habituation from the Skinner, such as spontaneous activities, exemplary methods are also a series of behaviorism theory from John Watson, and conditioning activities that are similar to behaviorism theory from Edwin Guthrie. This study includes the type of literature study research by finding reference theory that relevant to the cases or problems found. The data that have been obtained then analyzed by descriptive 
analysis method. The conclusions from this literature study includes 1, Pendidikan karakter merupakan tumpuan bangsa untuk merealisasikan visi pembangunan nasionalnya, yaitu merealisasikan bangsa yang memiliki karakter, akhlak yang luhur, moral, budaya, dan adab sesuai ideologi Pancasila dan Undang-Undang Dasar 1945. Mengembangkan nilai-nilai kepribadian pada siswa membutuhkan strategi pembelajaran dan keterampilan khusus, terlebih jika disesuaikan dengan karakteristik siswa yang merupakan generasi millenial. Kementerian Pendidikan dan Kebudayaan telah mengadopsi Profil Pelajar Pancasila sebagai salah satu Visi dan Misi Kementerian Pendidikan dan Kebudayaan. Hal ini sudah tercantum dalam Rencana Strategis Kementerian Pendidikan (2020-2024). Perlu bagi kita sebagai pendidik untuk memahami lebih lanjut mengenai Profil Pelajar Pancasila itu sendiri.

Profil Pelajar Pancasila ini merupakan salahsatu upaya pembentukan karakter siswa untuk menguatkan kompetensi akademik siswa. Menurut Suwartini (2017), Pendidikan karakter merupakan suatu prosedur yang menumbuhkan nilai - nilai karakter terhadap pelajar meliputi wawasan, pemahaman diri, keteguhan hati, dan komponen semangat serta langkah mengimplementasikan nilai-nilai, baik terhadap Tuhan YME, diri sendiri, orang lain, lingkungan, maupun masyarakat, sehingga akan terwujud insan kamil. Pendidikan karakter akan berhasil jika dilakukan secara bersama-sama, tidak hanya bergantung kepada guru. Pendidikan karakter merupakan kewajiban setiap pihak, artinya tidak hanya sekolah yang wajib menyelenggarakan pendidikan karakter, tetapi setiap pihak termasuk masyarakat juga harus memikul tanggung jawab yang sepadan. Dewantara dan Nurgiansah (2021) menyampaikan bahwa nilai-nilai Pancasila harus semakin dikuatkan dalam menghadapi Pandemi Covid-19 di Indonesia, dengan melibatkan partisipasi semua stakeholder terutama orang tua dan masyarakat.

\section{METODE}

Penelitian mengenai internalisasi nilai Pancasila dalam pembelajaran melalui penerapan Profil Pelajar Pancasila berbantuan Platform Merdeka Mengajar ini menggunakan metode deskriptif. Penelitian tersebut merupakan studi awal pada guruguru di sekolah penggerak yang pernah mendapatkan pelatihan Platform Merdeka Mengajar dari Kemendikbudristek. Sampel penelitian adalah guru-guru peserta Program Sekolah Penggerak Tahun 2021 sebanyak 60 orang dari berbagai provinsi.

Penelitian ini dilakukan selama satu bulan, yaitu mulai tanggal 15 Oktober 2021 sampai dengan 14 November 2021. Teknik pengumpulan data yang digunakan adalah kuesioner online, wawancara, dan dokumentasi. Kuesioner online menggunakan aplikasi formulir.kemdikbud. go.id, yang kemudian link-nya dibagikan ke WAG peserta Pelatihan Platform Merdeka Mengajar sebagai responden.

Analisis data dalam penelitian ini menggunakan model analisis interaktif yang meliputi: pengumpulan data, reduksi data, penyajian data dan penarikan kesimpulan yang dilakukan dalam bentuk interaksi dengan proses pengumpulan data sebagai suatu proses siklus. Pengecekan keabsahan data yang didapatkan menggunakan triangulasi, dengan mengecek keabsahan atau kebenaran data dengan hasil wawancara.

\section{HASIL PENELITIAN DAN PEMBAHASAN}

Pada dasarnya pendidikan karakter melalui penerapan Profil Pelajar Pancasila ini akan lebih optimal jika melibatkan kolaborasi antara upaya mandiri sekolah, masyarakat, pemerintah dan stakeholder terkait lainnya. Profil Pelajar Pancasila berdasarkan Visi dan Misi Kementerian Pendidikan dan Kebudayaan yang terdapat dalam Peraturan Menteri Pendidikan dan Kebudayaan Nomor 22 Tahun 2020 mengenai Rencana Strategis Kementerian Pendidikan dan Kebudayaan Tahun 2020-2024 yang berbunyi: "Pelajar Pancasila adalah perwujudan pelajar 
Indonesia sebagai pelajar sepanjang hayat yang memiliki kompetensi global dan berperilaku sesuai dengan nilainilai Pancasila, dengan enam ciri utama: beriman, bertakwa kepada Tuhan YME, dan berakhlak mulia, berkebinekaan global, bergotong royong, mandiri, bernalar kritis, dan kreatif". Menurut Galuh dan Dewi (2021), implementasi nilai-nilai Pancasila berupa pelaksanaan kewajiban sesuai ajaran agama yang dianut, hidup toleransi, peduli sosial, sopan, dan santun. Kalau kita cermati dari 6 ciri utama Pelajar Pancasila diatas sangat relevan dengan implementasi yang disampaikan berdasarkan hasil penelitian Galuh dan Dewi (2021).

Pendidikan karakter bangsa merupakan pengembangan nilai dalam pendidikan budaya dan karakteristik bangsa yang bersumber pada agama dan Pancasila, karena Indonesia adalah bangsa yang religius. Profil Pelajar Pancasila ini merupakan salah satu upaya pemerintah dalam menginternalisasi nilai-nilai Pancasila dalam masyarakat melalui pendidikan.

Menurut (Kaelani, 2013), internalisasi nilai-nilai Pancasila merupakan suatu upaya untuk meningkatkan kualitas keberhasilan dalam aktualisasi subjektif Pancasila, sehingga pengamalan Pancasila akan berlangsung secara tertib. Hubungan internalisasi nilai-nilai Pancasila yang dijabarkan melalui Profil Pelajar Pancasila tersebut dengan aktualisasi dan pengamalan Pancasila dapat dijelaskan dengan gambar 1.

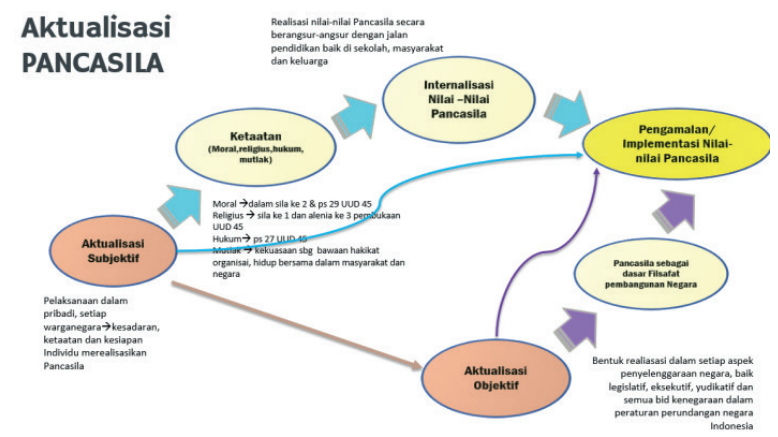

Gambar1 Bagan Alur Proses Aktualisasi Pancasila
Sebagai upaya mengoptimalisasi internalisasi nilai-nilai Pancasila melalui Profil Pelajar Pancasila, Kemendikbudristek tahun 2021 mengembangkan Platform Merdeka Mengajar, yang salahsatu menunya membahas mengenai Profil Pelajar Pancasila dan penerapannya. Ini sesuai dengan salah satu tujuan pengembangan PMM yaitu untuk memperkenalkan dan mengimplementasikan Profil Pelajar Pancasila sebagai dasar pembelajaran dengan paradigma baru, seperti yang dijelaskan dalam gambar 2 .

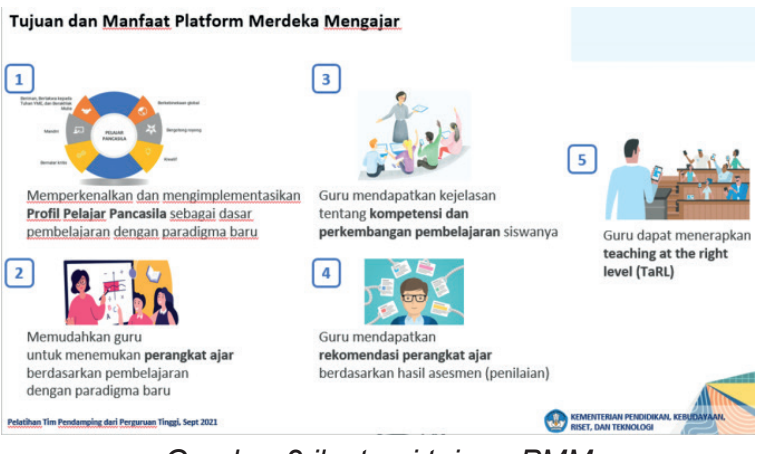

Gambar 2 ilustrasi tujuan PMM

Platform Merdeka Mengajar (PMM) tersaji dalam bentuk web based maupun android based, sehingga pengguna dapat mengakses melalui smartphone maupun komputer. Hasil penelitian menunjukkan bahwa mayoritas responden mengakses informasi Profil Pelajar Pancasila dalam aplikasi PMM menggunakan smartphone seperti yang disajikan dalam Gambar 3.

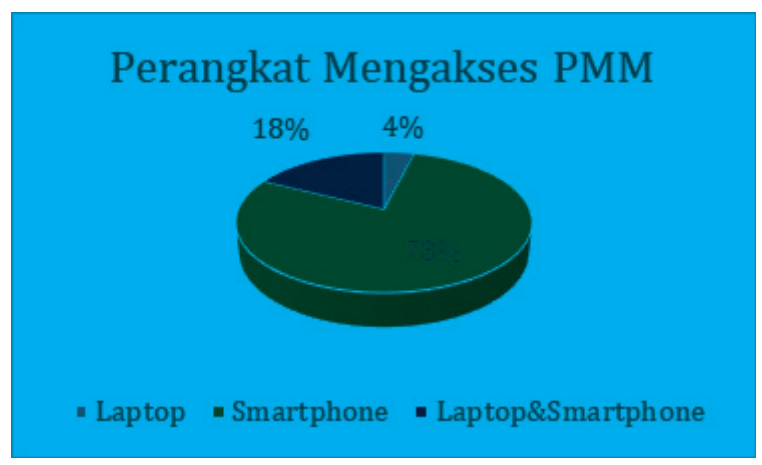

Gambar 3. Grafik Kecenderungan Jenis Perangkat untuk Mengakses Konten Profil Pelajar Pancasila dalam PMM 
Di dalam PMM, dijelaskan bahwa hakikat Profil Pelajar Pancasila adalah profil lulusan yang bertujuan menunjukkan karakter dan kompetensi yang diharapkan diraih dan menguatkan nilai-nilai luhur Pancasila peserta didik dan para pemangku kepentingan. Kegunaan Profil Pelajar Pancasila dijelaskan dalam aplikasi PMM yang meliputi: menerjemahkan tujuan dan visi pendidikan ke dalam format yang lebih mudah dipahami oleh seluruh pemangku kepentingan pendidikan, menjadi kompas bagi pendidik dan pelajar Indonesia, dan merupakan tujuan akhirsegala pembelajaran, program dan kegiatan di satuan pendidikan. Profil Pelajar Pancasila memiliki enam dimensi dan beberapa elemen di dalamnya, yaitu: beriman, bertakwa kepada Tuhan Yang Maha Esa, dan berakhlak mulia, berkebinekhaan global, mandiri, bergotong royong, bernalar kritis, dan kreatif.

Pertama. Beriman, bertakwa kepada Tuhan Yang Maha Esa, dan berakhlak mulia artinya bahwa Pelajar Pancasila wajib beriman dan bertakwa kepada Tuhan YME diwujudkan dengan akhlak yang baik pada diri sendiri, sesama manusia, alam, dan negara Indonesia. Profil yang pertama yang berorientasi pada nilai sila Pertama Pancasila Ini menjadi paling penting yang akan mendasari lima profil lainnya. Dengan berketuhanan, profil yang lain akan mudah dibentuk dan diterapkan dalam diri Pelajar Pancasila. Hal ini sesuai dengan kajian filsafat Pancasila, bahwa secara aksiologi, sila pertama memiliki tingkat dan bobot nilai tertinggi karena jelas mengandung nilai religus, sedangkan pada tingkat dibawahnya adalah keempat nilai manusia dasar. Nilai ketuhanan lebih tinggi dari nilai kemanusiaan, yang digambarkan dengan 5 Profil Pelajar Pancasila yang lain. Kedua. Berkebhinekaan global, hakikat profil yang kedua ini mengandung arti bahwa Pelajar Pancasila harus dapat mengenal dan menghargai budaya, serta mampu berkomunikasi dan berinteraksi antarbudaya. Mereka juga mampu berefleksi dan bertanggung jawab pada pengalaman kebhinekaan dan berkeadilan sosial.
Ketiga. Mandiri, artinya Pelajar Pancasila yang mandiri memiliki kesadaran akan diri dan situasi yang dihadapi, serta memiliki regulasi diri. Keempat. Bergotong Royong, maksudnya adalah Pelajar Pancasila gemar melakukan gotong royong dengan melakukan kolaborasi, memiliki kepedulian tinggi, dan berbagi dengan sesama. Kelima. Bernalar kritis, artinya bahwa Pelajar Pancasila mampu menganalisa dan mengevaluasi semua informasi maupun gagasan yang diperoleh dengan baik secara kritis. Mereka juga mampu mengevaluasi dan merefleksi penalaran dan pemikirannya sendiri. Keenam. Kreatif, maksudnya bahwa Pelajar Pancasila merupakan pelajar yang bisa menghasilkan gagasan, karya, dan tindakan yang orisinal. Mereka juga memiliki keluwesan dalam berpikir dalam mencari alternatif solusi permasalahan.

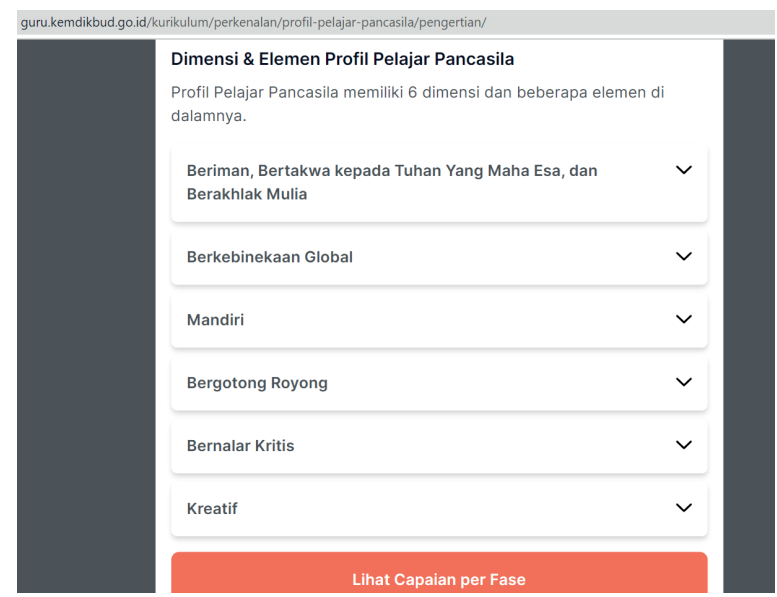

Gambar 4 tampilan konten Profil Pelajar Pancasila dalam PMM

Platform Merdeka mengajar dapat digunakan sebagai salah satu upaya dalam mengoptimalkan internalisasi nilai-nilai Pancasila yang terdapat dalam Profil Pelajar Pancasila. PMM ini sangat relevan dengan tuntutan kemajuan TIK dalam pendidikan di era milenial yang berbasis jaringan dan kemasan media yang visual grafis, termasuk visualisasi Profil Pelajar Pancasila dalam PMM. Hasil penelitian Bukhory dkk (2017) questionnaires, interviews, and tests and were analyzed using quantitative method, i.e. inferential statistics with the help of SPSS 16 program. Before performing 
the data analysis, a prerequisite test was done through normality and homogeneity test. Prerequisite test for hypothesis 1 indicated that the data were homogenous but not normal so that hypothesis 1 was further analysed using Mann Whitney $U$ test. Prerequisite test for hypothesis 2 showed that data were homogeneous and normally distributed so that the analysis for hypothesis 2 wasfurther carried out using an independent sample t-test. The results of this study show that (1 menyebutkan bahwa media visualisasi nilai-nilai Pancasila lebih efektif dibandingkan media gambar untuk meningkatkan sikap yang memuat nilai-nilai Pancasila. Dengan demikian diharapkan konten Profil Pelajar Pancasila dalam PMM dapat berperan dalam menginternalisasi nilai-nilai Pancasila.

Hasil penelitian menunjukkan bahwa peran PMM sebagai berikut. Pertama, sebagian besar responden aktif dalam mengakses informasi Profil Pelajar Pancasila di PMM $(80,4 \%)$ dengan tingkat keaktifan, sering dan sangat sering mengakses.

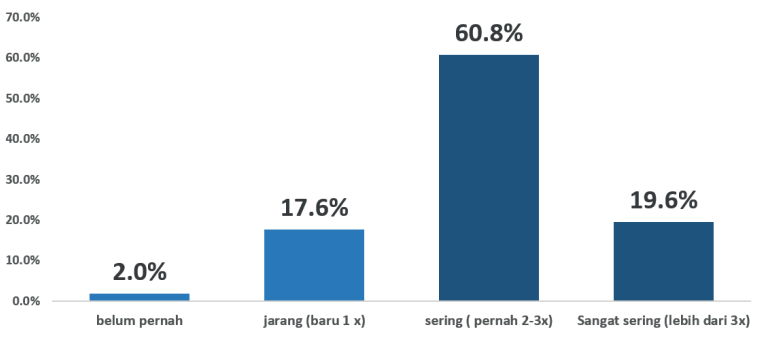

Gambar 5. Grafik tingkat keaktifan responden dalam informasi Profil Pelajar Pancasila

Hal ini menunjukkan bahwa konten PMM terkait penyediaan informasi Profil Pelajar Pancasila sangat menarik, sehingga sering diakses oleh responden. Hasil penelitian juga menunjukkan bahwa sekitar 96,1\% responden menyatakan konten Profil Pelajar Pancasila dalam PMM sangat menarik. Jika dibanding dengan mempelajari Profil Pelajar Pancasila dari sumber-sumber ajar offline (seperti buku, koran tercetak, majalah dansebagainya), maka konten Profil Pelajar Pancasila dalam PMM lebih menarik dan lebih mudah diakses pada era digital saat ini, terutama melalui smartphone.

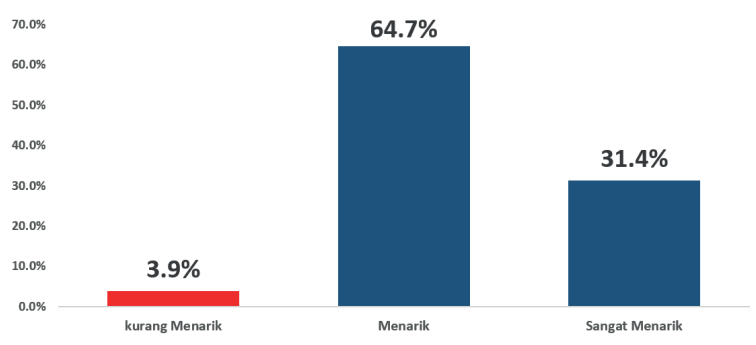

Gambar 6. Grafik kemenarikan konten Profil Pelajar Pancasila

Kedua, PMM berperan dalam mendukung internalisasi Pancasila melalui konten Profil Pelajar Pancasila. Pendapat ini didukung oleh hasil penelitian yang menyatakan bahwa lebih dari $92 \%$ responden mendukung pernyataan tersebut.

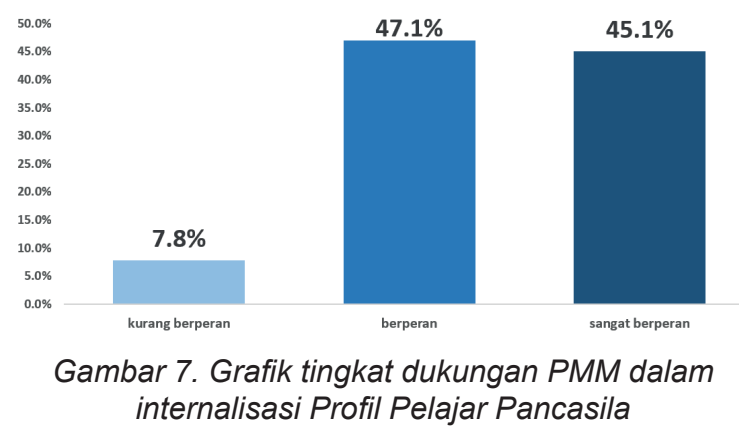

Dikatakan mendukung dalam internalisasi nilai Pancasila, karena informasi Profil Pelajar Pancasila memuat tentang perwujudan dari nilai-nilai yang dimiliki, diyakini dihayati oleh masyarakat sepanjang masa. Hal ini sesuai konsep bahwa Pancasila sebagai jati diri bangsa. Menurut Kaelani (2013), nilai Pancasila direalisasikan dalam sikap, tingkah laku dan perbuatan manusia Indonesia berupa prinsip-prinsip dasar yang terkandung dalam adat-istiadat, kebudayaan dan kehidupan keagamaan bangsa Indonesia. kensm Profil Pelajar Pancasila tersebut menggambarkan nilainilai Pancasila yang direalisasikan dalam sikap sehari-hari bagi pelajar yaitu Beriman, Bertakwa kepada Tuhan Yang Maha Esa, dan Berakhlak Mulia, berkebinekaan global, 
Mandiri, Bergotong royong, Bernalar Kritis, dan kreatif. Realisasi nilai-nilai Pancasila secara berangsur-angsur dengan jalan pendidikan di sekolah melalui penerapan Profil Pelajar Pancasila ini merupakan internalisasi nilai-nilai Pancasila yang dimaksud.

Pengimplementasian

Profil

Pelajar Pancasila dilakukan dengan mengintegrasikan dalam kegiatan pembelajaran baik di sekolah maupun saat penugasan di rumah. Dalam PMM juga disediakan buku panduan proyek penerapan Profil Pelajar Pancasila dalam pembelajaran. Ini sangat membantu guru dalam menerapkan konsep pembelajaran dengan paradigma baru yang mengintegrasikan nilai-nilai Pancasila melalui sikap yang sesuai dengan Profil Pelajar Pancasila. Hal senada juga disampaikan oleh Fatimah dan Dewi (2021), yaitu bahwa penerapan nilai-nilai Pancasila dalam dunia pendidikan dapat disisipkan pada setiap mata pelajaran, lingkungan sekolah yang mendukung, dan mencontohkan perilaku yang baik.

Dalam salah satu konten menu "Pusat Informasi Pembelajaran Paradigma Baru" pada aplikasi PMM, diberikan penjelasan mengenai konsep dan penerapan Profil Pelajar Pancasila di sekolah, serta panduan pengembangan proyek penguatan Profil Pelajar Pancasila dan budaya kerja. Profil Pelajar Pancasila tersebut harus diterapkan dalam bentuk karakter keseharian yang perlu dibangun dan dihidupkan dalam diri individu setiap pelajar melalui budaya sekolah, pembelajaran intrakurikuler, kokurikuler, maupun ekstrakurikuler. Dalam hal ini guru dituntut untuk lebih kreatif dan inovatif dalam mendesain pembelajaran agar dapat mengintegrasikan nilai-nilai Profil Pelajar Pancasila dalam pembelajaran.

Pendapat tersebut juga didukung dengan hasil penelitian yang menggambarkan bagaimana pemanfaatan konten Profil Pelajar Pancasila dalam PMM dapat mendukung internalisasi nilai Pancasila, sebagai berikut: 1) sebanyak $76.5 \%$ responden menyatakan bahwa konten tentang Profil Pelajar Pancasila dan target penerapannya sesuai dengan kebutuhan responden dalam mengajarkan Profil Pelajar Pancasila; dan 2) sebanyak 64,7\% responden menyatakan fitur informasi yang memuat Profil Pelajar Pancasila pada platform Merdeka Mengajar menarik responden untuk mempelajari informasi dalam fitur tersebut.

Menu Profil Pelajar Pancasila menjelaskan secara detail mengenai Profil Pelajar Pancasila. Dari data penelitian, sebanyak $76,5 \%$ responden menyatakan bahwa penjelasan Profil Pelajar Pancasila dalam aplikasi PMM sudah detail. Profil Pelajar Pancasila tersebut meliputi: Beriman, bertakwa kepada Tuhan YME, dan berakhlak mulia; berkebhinekaan global; mandiri; bergotong royong; bernalar kritis; dan kreatif. Dengan adanya informasi detail mengenai konsep dan contoh penerapan Profil Pelajar Pancasila dalam PMM, guru memperoleh referensi lain dalam menginternalisasi nilai Pancasila di sekolah. Di era digital ini, mayoritas guru memiliki smartphone sehingga ketika informasi Profil Pelajar Pancasila disajikan dalam aplikasi PMM, ini menjadi referensi yang lebih dekat untuk diakses. Guru tidak perlu ke perpustakaan untuk mencari referensi, atau membeli buku di toko buku. Cukup dari ponselnya, guru sudah dapat mengakses informasi terkait Profil Pelajar Pancasila setiap saat. Guru yang memiliki akun belajar id, dapat langsung membuka aplikasi PMM melalui smartphone atau laman dengan alamat https://guru. kemdikbud.go.id/ (Kemdikbud, 2021). Kemudian memilih menu Pusat Informasi Pembelajaran Paradigma Baru. Pilih sub menu Perkenalan, lalu mengakses Profil Pelajar Pancasila. Penjelasan mengenai Profil Pelajar Pancasila dalam aplikasi PMM, menunjukkan bahwa Profil Pelajar Pancasila sangat relevan dengan nilai-nilai Pancasila, 
yang sudah dikemas untuk pendidikan sebagai bagian dari program internalisasi nilai Pancasila di sekolah.

Tidak ada aplikasi apapun yang sempurna, begitu pula dengan aplikasi PMM terutama dalam menu Profil Pelajar Pancasila. PPM sendiri merupakan aplikasi yang "bertumbuh", sehingga akan terus berkembang baik fitur, menu maupun konten-kontennya. Menurut responden, PMM memiliki kelebihan dalam membantu internalisasi nilai Pancasila, yaitu : 1) memberikan kemudahan dalam mengakses informasi tentang Profil Pelajar pancasila; 2) kemudahan akses Platform Merdeka Mengajar menggunakan berbagai perangkat seperti laptop maupun telepon pintar; 3) kemudahan dalam penggunaan Platform Merdeka Mengajar.

Selain memiliki kelebihan, PMM juga memiliki kekurangan dalam membantu internalisasi nilai Pancasila, diantaranya menurut responden adalah: 1) beberapa guru kesulitan mengeksplorasi konten yang tersedia di dalam Platform Merdeka Mengajar karena perbedaan kompetensi TIK masingmasing guru, 2) karena bersifat online, terdapat kesulitan dalam menggunakan Platform Merdeka Mengajar bagi guru yang berdomisili di daerah yang tidak memiliki koneksi internet; dan 3) informasi dalam PMM mengenai Profil Pelajar Pancasila tidak bisa langsung dibagikan/diakses ke siswa melalui aplikasi. Siswandari dan Susilaningsih, (2013), menyatakan bahwa $63 \%$ dari guru bersertifikasi belum dapat menyampaikan materi dengan jelas, sehingga kemampuan pemanfaatan media dan teknologi pembelajaran, kemampuan mengikuti perkembangan TIK dan inovasi pembelajaran serta pengembangan keprofesian berkelanjutan masih perlu ditingkatkan. Untuk dapat mengakses dan mengeksplor konten PMM dengan optimal, dibutuhkan kemampuan TIK guru yang memadai. Sehingga mudah memahami isi konten dan kemudian menerapkannya dalam pembelajaran. Dengan adanya PMM yang menyajikan konten konsep dan penerapan Profil Pelajar Pancasila yang dapat diakses melalui smartphone dan laptop, diharapkan dapat membantu guru dalam mendapatkan referensi yang dapat diakses 24 jam sehari dan 7 hari dalam seminggu. Tidak seperti konten lainnya dalam PMM, konten Profil Pelajar Pancasila tidak memiliki fasilitas shareable. Jika ditambahkan fasilitas tersebut, maka akan lebih mudah bagi guru untuk membagikan ke peserta didik seperti beberapa konten di fitur lainnya di PMM.

PenyediaanmenuProfil PelajarPancasila dalam PMM diharapkan dapat membantu para guru dalam menginternalisasi nilai Pancasila kepada peserta didik. Ternyata dalam implementasinya banyak tantangan yang dihadapi oleh para guru. Tantangan yang ditemui oleh responden sebagai berikut: 1) keterbatasan sarana dan prasarana seperti koneksi internet, kuota internet, dan perangkat yang digunakan; 2) minimnya ketersediaan konten-konten pendukung yang menjelaskan Profil Pelajar Pancasila (video maupun bahan bacaan) pada Platform Merdeka Mengajar; dan 3) kesulitan untuk login ke dalam Platform Merdeka Mengajar karena proses autentifikasi. Beberapa responden menjelaskan bahwa tantangan terkait keterbatasan sarana dan prasarana TIK, bisa diatasi dengan komitmen sekolah dan stakeholder dalam mendukung pemanfaatan TIK. Hasil penelitian Anwas, (2015)East Java. The study used a qualitative approach with descriptive methods. Data were collected through observation and interviews of leaders of schools, the students, local governments and communities around the schools. The data analysis used descriptive analysis. The results of this study revealed that although the infrastructure and application systems is still relatively limited, but the school leadership has a strong commitment to using Information and Communication Technology in schools. Infrastructure limitations overcome by optimizing of Information and Communication Technology availability equipment by each students and the community. Utilizing Information and Communication Technology, teaching religion to be dynamic and interesting, more 
diverse media and content (text, images, audio, video, animation, and simulation bahwa walaupun secara infrastruktur relatif terbatas namun kebijakan dan komitmen pimpinan Pesantren Rakyat sangat kuat sehingga pemanfaatan Teknologi Informasi dan Komunikasi dapat optimal

Tantangan-tantangan tersebut, menunjukkan bahwa PMM dalam perannya membantu guru memahami dan menerapkan Profil Pelajar Pancasila pada siswa bukan merupakan hal yang sederhana. Masih diperlukan proses dan upaya untuk terus meningkatkan kualitas sehingga tantangan-tantangan tersebut bisa diatasi. Menurut Susilawati (2019) belum semua guru menerapkannya dalam pembelajaran. Intensitas penerapan model pembelajaran inovatif tersebut masih rendah. Oleh karena itu, perlu diobservasi dan dievaluasi penerapannya sebagai bahan masukan terhadap penyempurnaan model pembelajaran tersebut di tahun-tahun berikutnya. Tujuan penelitian ini adalah untuk mengetahui gambaran pelaksanaan penerapan model pembelajaran inovatif di SMPPesatBogor.Penelitianinimenggunakan pendekatan penelitian kuantitatif dengan metode analisis kuantitatif deskriptif. Subyek/Responden penelitian ini adalah semua guru SMP Pesat. Pengumpulan data dilakukan dengan menggunakan pedoman observasi, wawancara, dan kuesioner. Hasil penelitian menunjukkan bahwa 1, bagi sekolah yang terkendala dengan jaringan internet, penerapan e-pembelajaran yang memanfaatkan Rumah Belajar bisa dilakukan secara offline. Begitu juga penerapan e-pembelajaran menggunakan PMM ini, bagi yang terkendala jaringan internet bisa dimanfaatkan secara offline dengan mengunduh terlebih dahulu disimpan ke USB atau hard disk eksternal kemudian diakses secara offline.

Aplikasi PMM yang saat ini hanya dapat diakses dengan akun belajar id ini perlu lebih disederhanakan lagi proses autentifikasinya sehingga lebih user friendly. Pusdatin Kemdikbudristek sebagai penanggungjawab akun belajar id, perlu lebih mengoptimalkan kuantitas pemanfaatan akun tersebut, sehingga semua guru di Indonesia dapat terjangkau. Ini menjadi langkah pertama agar upaya internalisasi nilai Pancasila memanfaatkan PMM dapat lebih optimal menjangkau semua guru di Indonesia.

Disamping tantangan yang dihadapi para guru dalam menginternalisasi nilai Pancasila melalui Platform Merdeka Mengajar, responden melihat peluang pemanfaatan PMM dalam membantu guru menginternalisasi nilai Pancasila. Pendapat tersebut didukung oleh pendapat responden sebagai berikut: 1) Platform Merdeka Mengajar memiliki peluang besar untuk menginternalisasi nilai Pancasila apabila para guru telah menguasai aplikasi, menu dan semua fasilitas yang terdapat dalam platform; 2) sangat berpeluang apabila penerapan dan pemanfaatan Platform Merdeka Mengajar sudah merata dan digunakan oleh seluruh guru di Indonesia; dan 3) sangat besar peluang internalisasi nilai Pancasila melalui pemanfaatan Platform Merdeka Mengajar, karena di dalamnya ada penjelasan penerapan Profil Pelajar Pancasila di sekolah. Profil Pelajar Pancasila merupakan karakter dan keseharian yang dibangun dalam keseharian dan dihidupkan dalam diri individu setiap pelajar melalui budaya sekolah, pembelajaran intrakurikuler, kokurikuler, maupun ekstrakurikuler. dan juga tersedia panduan pengembangan proyek penguatan Profil Pelajar Pancasila dan budaya kerja.

Nurhadianto (2014), menyatakan bahwa internalisasi nilai-nilai pancasila di kalangan remaja dirasa sangat diperlukan agar sikap dan perilaku para remaja senantiasa dijiwai nilai-nilai luhur Pancasila. Pancasila merupakan dasar filsafat negara Indonesia, yang nilai-nilainya telah ada pada bangsa Indonesia sejak zaman dahulu, berupa nilainilai adat istiadat, kebudayaan dan nilai agama. Dengan demikian sila Ketuhanan yang Maha Esa nilainya telah ada pada bangsa indonesia sebagai kausa materialis.

Berdasarkan data hasil penelitian, maka terdapat beberapa saran/masukan dari responden, sebagai bahan pertimbangan 
bagi tim pengembang aplikasi PMM dalam meningkatkan kualitas layanan sesuai kebutuhan dan masukan dari pengguna. Saran dan masukan yang dimaksud meliputi:1) perlu ditingkatkan kemudahan dalam proses login ke dalam Platform Merdeka Mengajar; 2) perlu disiapkan Platform Merdeka Mengajar versi offline, mengingat ketidakmerataan koneksi internet di wilayah Indonesia; 3) dalam PMM perlu dilengkapi fasilitas shareable dan unggah praktik baik penerapan praktik baik penerapan Profil Pelajar Pancasila, dan perlu diperbanyak pelatihan-pelatihan pengembangan proyek penguatan Profil Pelajar Pancasila.

\section{SIMPULAN DAN SARAN}

\section{Simpulan}

Sekolah, guru dan siswa memiliki kewajiban yang sama dalam mengimplementasikan nilai Pancasila. Penanaman nilai Pancasila dengan internalisasi nilai Pancasila berupa Profil Pelajar Pancasila seperti yang dijelaskan dalam salah satu menu di PMM sangat menarik. Hakikat Profil Pelajar Pancasila yang dijelaskan di PMM, menggambarkan nilai-nilai Pancasila yang diinternalisasi dalam pembelajaran di sekolah meliputi beriman, bertakwa kepada Tuhan Yang Maha Esa, dan Berakhlak Mulia, berkebinekaan global, mandiri, bergotong royong, bernalar kritis, dan kreatif.

Platform Merdeka Mengajar sangat membantu dalam penerapan Profil Pelajar Pancasila pada pembelajaran paradigma baru.Profil Pelajar Pancasila diterapkan dalam karakter keseharian yang dibangun dan dihidupkan dalam diri individu setiap pelajar melalui budaya sekolah, pembelajaran intrakurikuler, kokurikuler, maupun ekstrakurikuler di sekolah.

\section{Saran}

Secara praktis, bagi tim pengelola PMM perlu meningkatkan kualitas dan kuantitas konten Profil Pelajar Pancasila, terutama dalam detail penjelasan dan contoh-contoh implementasi masing-masing Profil Pelajar Pancasila tersebut dengan lebih banyak variasi media pembelajaran yang menarik. Pemanfaatan konten Profil Pelajar Pancasila dalam aplikasi PMM berdampak signifikan memudahkan guru dalam menginternalisasi nilai-nilai Pancasila melalui penerapan Profil Pelajar Pancasila. Oleh karena itu, perlu ditingkatkan keaktifan dan motivasi para guru dalam mengoptimalkan pemanfaatan PMM. Bagi guru yang belum lancar dalam menggunakan PMM, mereka harus meningkatkan kemampuan TIK agar dapat mengeksplorasi aplikasi PMM secara mandiri. PMM perlu terus dikembangkan dan ditingkatkan baik dari sisi kualitas isi/layanan dan strategi penerapan PMM agar lebih efektif, serta didukung dengan optimalisasi pembagian akun belajar id keseluruh guru di Indonesia.

Bagi para pengambil kebijakan pendidikan, sekolah, dan guru, hasil penelitian ini dapat dijadikan pertimbangan dalam meningkatkan kualitas pelaksanaan pendidikan karakter siswa melalui implementasi Profil Pelajar Pancasila berbantuan PMM, terutama pada saat pembelajaran yang masih bersifat pertemuan tatap muka/PTM terbatas dan masih bergantung pada TIK dalam melaksanakan pembelajaran selama pandemi Covid-19 dan new normal.

Secara akademik, hasil penelitian ini dapat dijadikan referensi dan kajian awal bagi penelitian-penelitian berikutnya yang menggali strategi pemanfaatan PMM dalam menginternalisasi nilai-nilai Pancasila agar lebih optimal. 


\section{PUSTAKA ACUAN}

Anwas, O. M. (2015). Pemanfaatan Teknologi Informasi dan Komunikasi pada Pesantren Rakyat Sumber Pucung Malang. Jurnal Pendidikan dan Kebudayaan, 21(3), 207. https://doi. org/10.24832/jpnk.v21i3.187

Buchory, Rahmawati, S., \& Wardani, S. (2017). Pengembangan Media Pembelajaran Visualisasi Nilai-Nilai Pancasila Berbasis Teknologi Informasi Dan Komunikasi. Jurnal Cakrawala Pendidikan, 36(3), 502-521. https://doi. org/10.21831/cp.v36i3.12748

Dewantara, J. A., \& Nurgiansah, T. H. (2021). Strengthening Pancasila Values During the Covid-19 Pandemic. Edukatif: Jurnal IImu Pendidikan, 3(4), 2411-2417.

Fatimah, S., \& Dewi, D. A. (2021). Pengimplementasian Nilai-Nilai Pancasila Dalam Membangun Karakter Jati Diri Anak Bangsa. Antropocene: Jurnal Penelitian IImu Humaniora, 1(5), 1-7. https://journal.actual-insight.com/ index.php/antropocene/article/view/205

Galuh, A. D., \& Dewi, D. A. (2021). Implementasi Nilai-Nilai Pancasila Melalui Pendidikan Pancasila (Studi Kasus Mahasiswa PGSD UPI Kampus Cibiru). Jurnal Rhizome: Jurnal Kajian IImu Humaniora, 1(5), 1-5. https:// journal.actual-insight.com/index.php/ rhizome/article/view/233

Kaelani. (2013). Filsafat Pancasila. Yogyakarta: Paradigma.

Kalderanews.com. (2020). Begini 6 Profil Pelajar Pancasila Menurut Mendikbud Nadiem Makarim. https://www. kalderanews.com/2020/05/begini6-profil-pelajar-pancasila-menurutmendikbud-nadiem-makarim/

Kemdikbud. (2021). Profil Pelajar Pancasila. https://guru.kemdikbud.go.id/

Kosim, M. (2011). Urgensi pendidikan karakter. Jurnal Karsa, IXI(1), 85-92.

KPAI. (2020a). Data Kasus Pengaduan Anak. https://bankdata.kpai.go.id/ tabulasi-data/data-kasus-pengaduananak-2016-2020
KPAI. (2020b). Rincian Data Kasus Berdasarkan Klaster Perlindungan Anak. https://bankdata.kpai.go.id/ tabulasidata/data-kasus-per-tahun/ rincian-datakasus-berdasarkan-klasterperlindungananak-2011-2016

Peraturan Menteri Pendidikan dan Kebudayaan Nomor 22 Tahun 2020 tentang Rencana Strategis Kementerian Pendidikan, Pub. L. No. 22 (2020).

Nurhadianto. (2014). Internalisasi Nilai-Nilai Pancasila dalam Upaya Membentuk Pelajar Anti Narkoba. Jurnal Pendidikan IImu Sosial, 23(2), 44 . https://doi. org/10.17509/jpis.v23i2.1618

Perdana, N. S. (2018). Penguatan Pendidikan Karakter di Sekolah dalam Upaya Pencegahan Kenakalan Remaja. Jurnal Edutech, 17(1), 32-54. https://doi. org/https://doi.org/10.17509/e.v1i1.9860

Siswandari, \& Susilaningsih. (2013). Dampak Sertifikasi Guru Terhadap Peningkatan Kualitas Pembelajaran Peserta Didik. Jurnal Pendidikan dan Kebudayaan, 19(4), 487-498. https:// doi.org/10.24832/jpnk.v19i4.305

Susilawati, E. (2019). Penerapan Model Pembelajaran Inovatif Yang Memanfaatkan Portal Rumah Belajar di Smp Pesat Bogor. Jurnal Teknodik, 23(1), 41-54. https://doi.org/10.32550/ teknodik.v0i0.367

Suwartini, S. (2017). Pendidikan Karakter dan Pembangunan Sumber Daya Manusia Keberlanjutan. Jurnal Pendidikan, 4(1), 220-234. https://media.neliti.com/ media/publications/259090-pendidikankarakter-dan-pembangunan-sumbe0cf1b5a.pdf 
